\title{
Ülke Kredi Riski Derecelendirmede: İç Ekonomik Veriler ile Temerrüt Olasılığı İlişkisinin İncelenmesi*
}

\author{
Sovereign Credit Risk Rating: Examining the Relations between Domestic \\ Economy Data and the Probability of Default
}

\section{Merve KIRKIL ${ }^{1}$ (D)}

\section{öz}

Ülke Kredi Derecelendirme notları finansal piyasalarda büyük bir öneme sahiptir. Derecelendirme notlarının piyasada fon ihtiyacı olanlar ve yatırımcılar arasında ortak bir dilde bilgi aktarımını sağlama fonksiyonu bulunmaktadır. Ülke Kredi Derecelendirme notları, ülkelerin borçlanma maliyetlerini etkilemektedir. Aynı zamanda yabancı yatırımcıların ve fonların ilgili ülkede yatırım yapma kararlarını etkilemektedir. Ülke Riski Derecelendirme yaklaşımlarında; ödemeler dengesi, iç ekonomik göstergeler, dış varlık verileri, finansal sektörün durumu, gelir ve nüfus verileri, kamu maliyesi verileri değerlendirmelerde kullanılmaktadır. Bu çalışmada, iç ekonomik veriler inceleme kapsamına alınarak ülkelerin temerrüt olasılığına olan etkileri araştırılmıştır. Çalışmada lojistik regresyon yöntemi kullanılmıştır. Ülke temerrüt verileri incelenerek kategorik hale getirilmiştir. GSYIH verileri, döviz kuru ve tüketici fiyatları artış oranı verilerinin temerrüt olasılığını açıklama gücünün yüksek olduğu görülmüştür. Çalışmada G20 ülkeleri kapsama alınmış ve 2008-2017 yılları arası incelenmiştir. Çalışma sonucunda, dolar kurundaki artışların ve bu artışlar nedeniyle USD cinsinden GSYIH'nın azalması ülkelerin temerrüt olasılığı artıran bir etken olmuştur.

Anahtar kelimeler: Ülke kredi derecelendirme, Ülke rating, Ülke temerrüt olasılığı, Lojistik regresyon, G20

Jel Sınıflaması: E60, H10, G20
*Bu çalışma, İstanbul Üniversitesi, Sosyal Bilimler Enstitüsü Iktisat Doktora Programında Prof. Dr. Halil TUNALI danışmanlığında yürütülen doktora tezimden üretilmiştir.

'Doktora Öğrencisi, İstanbul Üniversitesi, Sosyal Bilimler Enstitüsü, Iktisat Anabilim Dalı, Doktora Öğrencisi, İstanbul, Türkiye

ORCID: M.K. 0000-0002-7080-1474

\section{Sorumlu yazar/Corresponding author:} Merve KIRKIL,

İstanbul Üniversitesi, Sosyal Bilimler Enstitüsü, İktisat Anabilim Dalı, İstanbul, Türkiye

E-posta/E-mail: mervekirkil@gmail.com

Başvuru/Submitted: 10.12 .2020

Revizyon Talebi/Revision Requested:

12.12.2020

Son Revizyon/Last Revision Received:

22.12.2020

Kabul/Accepted: 18.01.2021

Atıf/Citation: Kirkil, M. (2021). Ülke kredi riski derecelendirmede: İç ekonomik veriler ile temerrüt olasılığı ilişkisinin incelenmesi. iktisat Politikası Araştırmaları Dergisi - Journal of Economic Policy Researches, 8(1), 57-74. https://doi.org/10.26650/JEPR838626 


\begin{abstract}
Sovereign credit ratings have gained importance in financial markets. Sovereign ratings have the function of providing necessary information in a common language between market participants who need funds and investors. Sovereign credit ratings affect countries' borrowing costs. Additionally, it affects the decisions of foreign investors and investment funds, to invest in the related country. In sovereign credit risk approaches, various data is used for assessment such as balance of payment, domestic economy indicators, external economy, financial sector status, income and population data, and public finance data. In the scope of this study, the relation between domestic economy indicators and the probability of default are investigated. The logistic regression method was used in the study. The Sovereign default data is analyzed and categorized. It was observed that GDP data, exchange rate, and consumer price growth rate are high explanatory variables that explain the probability of default. G20 countries were included in the study and examined between the years 2008-2017. As a result of the study, the increase in USD exchange rate and a decrease in the GDP in USD have been a factor that increases the probability of default for countries.
\end{abstract}

Keywords: Sovereign credit rating, Sovereign rating, Sovereign default, Logistic regression, G20

Jel Classification: E60, H10, G20

\title{
EXTENDED ABSTRACT
}

Sovereign credit ratings are quite important for relevant countries' access to finance and their credibility in financial markets. Credit rating agencies do not recommend a buy or sell, they only produce ratings for issuers. In practice, investors may prefer to use ratings in order to manage their portfolios. Sovereign ratings provide information about willingness to pay its debt and especially for the debt service quality of the sovereign. Cantor and Packer, investigated the main factors which affect sovereign rating. They also examined the market price and sovereign rating. Afonso continued to study factors of sovereign rating and to expand the scope of whether developed and developing countries produce a similar response to the same rating sub-factors.

As defined before, a sovereign rating consists of a large variety of information that predicts optimal creditworthiness. The main items are balance of payment, domestic economy indicators, external economy, financial sector status, income and population data, and public finance data. The Sovereign rating methodolgy of credit agencies was investigated in section three. Standard \& Poor (S\&P) Moody's, and Fitch are the leaders in credit rating agencies. The S\&P rating approach consists of institutional assessment, economic assessment, external assessment, fiscal assessment, and monetary assessment. The institutional and economic profiles and flexibility and performance profiles give sovereign rating results. Moody's rating approach consists of economic strength, institution and governance strength, fiscal strength, and susceptibility to event risk. Government financial strength and susceptibility to event risks give sovereign rating results. The Fitch rating approach consists of macroeconomic outlook, policies and prospects, public finances, external finances, and structural features. Those agencies use the GDP, GDP growth rates, 
GDP per capita, and consumer price index, etc. to assess domestic economy profiles. Additionnaly, when the GDP is not concentrated in certain sectors and includes economic diversity as a feature, it increases resistance to economic shocks. It affects the credibility assessment of sovereigns positively. Another important variable is GDP per capita. GDP per capita is used as a measure of income and a high level of value is considered favorably in terms of the credibility of the country.

The main goal of this study is to indicate the relation between domestic economy indicators and the probability of default. The default data was obtained the Bank of England and the Bank of Canada databases and categorized in order to use for regression. A categorized version of the default data was used as a dependent variable in the model. A broad set of independent variables were analyzed such as the GDP data, GDP growth rate, exchange rate, consumer price growth rate, reserve money status, and gross domestic investments. The logistic regression method was used in the study. Fundamentaly, the logistic regression method returns the probability of realization of the dependent variable Y. After the necessary data optimization was made, an interactive grouping was performed on the data. Within the scope of the study, variables with a correlation above $60 \%$ were not included in the regression analysis. In this study, some of the analyzed data was reserved for use in a validation study. Seventy percent of the analyzed data was used for model development and 30\% was used for testing the developed model. The exchange rate, consumer price index, gross domestic investments, and the GDP(USD) were used in the model as explanatory variables. The weight of the GDP data in the model was $29 \%$, the consumer price index data was $27 \%$, and the local currency on USD basis was $24 \%$. These three types of data are highly effective in predicting a country's probability of default. As a result of the study, non default probability was produced. It was observed that when there was an increase in the USD rate level, there is a natural decrease in the GDP levels in USD due to the increase in exchange rates. This situation was reflected in the indicators to increase the probability of default data. 


\section{Giriş}

Ülke riski derecelendirme çalışmalarında analitik yöntemlere dayalı niceliksel yaklaşımlar ve uzman görüşe dayalı niteliksel yaklaşımlar birlikte kullanılarak nihai değerlendirmeye ulaşılmaktadır. Ülke kredibilitesi pek çok parametrenin bir araya gelmesiyle değerlendirilmektedir. Ekonomik veriler, politik ve yönetişim kalitesinin değerlendirilmesi, maliye politikaları ve para politikasının değerlendirilmesi, borç yükünün analiz edilmesi, ödemeler dengesinin incelenmesi, bu değerlendirmenin önemli unsurları arasında yer almaktadır. Bu değerlendirmede, halka açık veriler yardımıyla süreci şeffaf bir şekilde ortaya konabilen bir rating metodolojisi oluşturmak gittikçe önem arz eden bir konu haline gelmiştir.

Bu çalışmada, ülke riski derecelendirme sürecinin önemli bir parçası olan iç ekonomi verileri üzerinde bir çalışma yapılmış ve temerrüt olasılığına olan etkisi lojistik regresyon yöntemiyle analiz edilmiştir. İkinci bölüm olan literatür araştırması kısmında, ülke derecelendirme, ülke borçlanmaları ve ülke temerrütleri hakkındaki önemli çalışmalara yer verilmiştir. Üçüncü bölümde piyasa hakimiyeti yüksek olan derecelendirme kuruluşlarının ülke riski derecelendirme metodolojilerine değinilmiş ve önemli noktaları vurgulanmıştır. Dördüncü bölümde çalışmada kullanılan veri seti bağımlı ve bağımsız değişkenler bazında anlatılmış, analiz öncesinde ihtiyaç duyulan veri iyileştirme çalışmalarına kısaca değinilmiştir. Analiz için tercih edilen lojistik regresyon yaklaşımının teorik çerçevesi de bu bölümde özet bir şekilde açıklanmıştır. Beşinci bölümde uygulama sonuçları ve model çıktılarına yer verilmiştir. Altıncı bölüm olan sonuç bölümünde ise ülkeler bazında üretilen temerrüt etmeme olasılık değerleri gösterilmiş ve yorumlanmıştır.

\section{Literatür Taraması}

Cantor ve Packer (1995), ülke kredi riski ve üretilen rating notlarının ülkelerin finansmana erişimindeki etkisi üzerinde çalışmalarını yapmıştır. Ayrıca, derecelendirme kuruluşları tarafından atanan rating notlarının anlaşılabilirliği ve kamuoyu tarafından yorumlanması konusunu da çalışma kapsamına almışlardır. Çalışmada, Moody’s ve S\&P tarafından verilen ülke notları incelenerek, verilen notlar arasında uyumsuzluk olduğu gözlenmiştir. Bu durumun ise, kurumların not üretme sürecinde sübjektif unsurlar kullanmasından kaynaklandığı ileri sürülmüştür.

Eaton ve Fernandez (1995), ülke borçlanmalarına yönelik çalışmasında gelişmekte olan ülkelerin ticari bankalardan aldıkları borçları dikkate alarak çalışmalarını yapmış ayrıca, ülkenin mali yükünü artıran diğer finansman türlerinin neler olduğu ve bu finansman türlerinin ülke ve borç verenler açısından ne tür dışsal risklere neden olacağı incelenmiştir. Ayrıca, borç yapılandırmalarının ülke borç yükünü azaltmaya olan etkileri çalışma kapsamına alınmıştır. 
Cantor ve Packer (1996), Ülke Kredi Riskinin Belirleyicileri ve Etkileri başlıklı çalışması literatürde önemli bir yer tutmaktadır. Cantor ve Packer (1996), ülke ratingini belirleyen faktörleri araştırmış ve altı faktörün önemli bir rol oynadığını tespit etmiştir. Bunlar; kişi başı gelir, GSYİH büyümesi, enflasyon, ekonomik gelişmişlik seviyesi ve temerrüt geçmişi verileridir. Kişi başına düşen gelirin yüksek olması, düşük enflasyon oranları ve dış borcun az olması genellikle yüksek rating notlarıyla ilişkilendirilmiştir. Ayrıca, kredi derecelendirme kuruluşlarının görüşlerinin piyasa spreadlerini etkilediği gözlenmiştir.

Juttner ve McCarthy (1997), ülke rating notları üzerine bir çalışma yaparak rating modellemesine katkıda bulunmuştur.

Haque, Mark ve Mathieson (1998), ülkenin kredi derecelendirme notunun belirlenmesinde politik ve ekonomik değişkenlerin etkisini incelemiştir. Ülke kredi değerliliğinin öncelikli olarak ekonomik verilerden etkilendiği, ekonomik verilerin değerlendirmeye alınmasının ardından politik etmenlerin sonuca katkı sağladığı belirtilmiş, ekonomik veriler içerisinde ülkenin borç karşılama servisinin birinci öncelikli olduğu vurgulanmıştır.

Roubini (2001), borç sürdürülebilirliği ve ülkelerin iflas edip etmediğinin değerlendirilmesi konusunda çalışma yapmıştır. Ülkenin dış ticaret dengesi, cari dengesi, mali sağlamlığı, yabancı borçları gibi faktörleri araştırmasında kullanmış, toplam borcun GSYİH'dan aldığı payları incelemiştir. Borç rasyosu borç sürdürülebilirliği açısından önemi bir gösterge olarak değerlendirilmiştir. Ülke iflasının değerlendirmesinde, likidite sorunu olup olmadığı incelenmiş, borçların sürdürülebilir olduğu durumlarda likidite problemlerinin oluşmayacağı tespitinde bulunmuştur.

Afonso (2003), Kredi derecelendirme notlarını etkileyen faktörler üzerinde çalışmaları derinleştirmiş ve ülke gelişmiş seviyeleri ile ilişkisini de incelemiştir. Afonso, Agnello ve Furceri (2010), ülke derecelendirme notlarının, ülkelerin borçlanma maliyetleri üzerinde etkilerini araştırmış ve belirgin şekilde etkileşim olduğunu ifade etmiştir.

Reinhart (2002), Temerrüt, Kur Krizleri ve Ülke Riski Derecelendirmeleri başlıklı çalışmasında, kur krizleri ve ülke temerrütleri arasındaki ilişkiyi incelemiş ve gelişmekte olan pazarlarda kur krizleri ve ülke temerrütleri arasında yüksek korelasyon tespit etmiştir. Ayrıca, kredi derecelendirme kuruluşlarının ratinglerinin yaklaşmakta olan kur krizleri konusundaki zayıf tahminciler olduğunu vurgulamıştır.

Kraay ve Nehru (2003), ülke dış borçlarının sürdürülebilirliği hakkında, Paris Klup borçlanmaları, IMF borçları ve diğer dış borçları dikkate alarak bir çalışma yapmıştır. Borç stresinin ortaya çıkmasının nedenleri olarak, toplam borç yükleri, uygulanan politikalar ve ekonomik şokların oluşması gösterilmiştir. 
Manasse, Roubini ve Schimmelphennig (2003), ülke borç krizlerinin tahmin edilmesine yönelik bir erken uyarı sistemi çalışması yapmıştır. Çalışma, 47 ülkenin 1970-2002 yılları arasındaki verilerinden hareketle hazırlanmıştır. Manasse ve Roubini (2009), ülke borç krizleri ile ilgili temel göstergelerin açıklandığı bir çalışma daha yapmışlardır. Çalışmada, borç krizi öncesindeki ekonomik ve politik koşullarla, ekonomideki temel kırılganlıklar incelenmiştir. Borç krizine giren ülkelerin temel karakteristikleri ve hangi değerler için güvenli bölgede olabilecekleri belirlenmiştir.

Panizza, Sturzenegger ve Zettelmeyer (2009), ülke temerrütlerinin hukuki ve ekonomik perspektifini birlikte ele almış ve incelenen ülkelerdeki kurumsal yapıların gelişmişliği ile temerrüt halindeki maliyetlerin azaltılması arasında bir ilişki olduğunu vurgulamıştır.

Butler ve Fauver (2008), ülkelerin kurumsal çerçevesi ve ülke kredi derecelendirme notları arasında ilişki üzerine çalışmış ve ülkelerdeki kurumsal ve hukuki altyapının gelişmişliği ve siyasi kurumların kalitesinin ülke notlarını belirlemede etkili olduğunu vurgulamışlardır.

Afonso ve Gomes (2011), ülkelerin mali dengesizliklerinin, ülke kredi derecelendirme notuna etkileri üzerine çalışmışlardır. Mali açıdan kötüleşen ülkelerin rating notlarının en iyimser model senaryosunda bile kötüleştiği sonucuna ulaşmışlardır.

Hill, Bissoondoyal-Bheenick ve Faff (2017), ülke kredi derecelendirme notlarının belirlenmesinde kullanılan ekonomik ve mali verilerin gelişmiş ve gelişmekte olan ülkelerin aynı açıklama gücüne sahip olmadığı konusunu araştırmışlardır. Gelişmekte olan ülkelerdeki belirleyicilerin farklı olduğu, makroekonomik göstergelerin rating notunu net olarak belirleyemediği ve kalitatif faktörlerin rating notunda etkili olduğu sonucuna ulaşmıştır.

\section{Kredi Derecelendirme Kuruluşlarının Ülke Riski Değerlendirme Yaklaşımları}

Ülke riski değerlendirme ve derecelendirme yaklaşımlarında piyasa hakimiyeti olan derecelendirme kuruluşlarının yaklaşımları incelenmiştir. Veriler incelendiğinde Moody’s, S\&P ve Fitch'in piyasa hakimiyetine sahip olduğu görülmektedir (Infrangilis, 2012). 
Grafik 1. Derecelendirme Kuruluşları Piyasa Payı

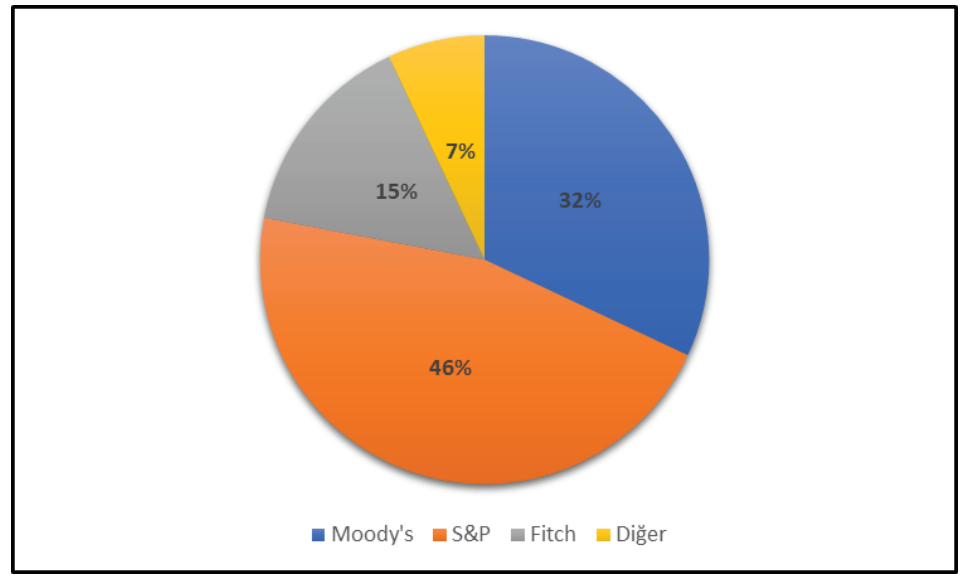

Kaynak: European Securities and Market Authority

S\&P derecelendirme yaklaşımında, kurumsal değerlendirme, ekonomik değerlendirme, dış ekonomik değerlendirme, mali değerlendirme ve para politikası değerlendirmesi ayrı ayrı yapılmaktadır. Kurumsal ve ekonomik değerlendirme sonuçlarının konsolide edilmesinden Kurumsal ve Ekonomik Görünüm sonucu elde edilmektedir. Diş ekonomi değerlendirmesi, mali değerlendirme, para politikası değerlendirme sonuçlarından ise Esneklik ve Performans Görünümüne ulaşılmaktadır. Bu iki ana sonuç da bir matriste konumlandırılarak rating değerlendirmesi elde edilmektedir. Elde edilen rating değerlendirmesinin ardından ilave düzeltmeler de yapılabilmektedir. S\&P çalışmasında da önemli bir yer tutan ekonomik değerlendirme, ülkedeki gelir düzeyi, büyüme beklentileri ve ekonomik çeşitlilik ve volatilite değişkenlerinden hareketle yorumlanmaktadır. Kişi başına düşen GSYİH gelir ölçütü olarak kullanılmaktadır ve yüksek olması ülke kredibilitesi açısından olumlu değerlendirilmektedir. Kişi başına düşen GSYİH'nın yüksek olması vergi tabanını ve talep yönlü ekonomik büyümeyi olumlu etkilemektedir. Büyüme beklentilerinin açıklanması için reel GSYİH trendi incelenmektedir. Ayrıca, GSYİH’nın belirli sektörlerde yoğunlaşmamış olması ve ekonomik çeşitlilik içermesi, ekonomik şoklara karşı direnci artıran bir özelliktir. Bir ekonomik döngü içerisindeki olumlu GSYİH büyümesi ülke kredibilitesini iyi yönde etkilemektedir (S\&P, Sovereign Rating Methodology, 2019).

Moody's derecelendirme yaklaşımında niteliksel ve niceliksel yaklaşımlar birlikte kullanılmaktadır. Ancak, ilk olarak bir skorkart modeliyle değerlendirmeler yapılmakta sonrasında düzeltme faktörleri dikkate alınarak nihai derecelendirmeye gidilmektedir. Skorkart yaklaşımında, ekonomik sağlamlık, kurumlar ve yönetişim gücü, mali sağlamlık ve olay riskine duyarlılık şeklinde dört ana değerlendirme bloğu bulunmaktadır. Ekonomik 
sağlamlık, kurumlar ve yönetişim gücü alt faktörlerinin sonuçları ekonomik dayanıklılık konusunda çıkarımda bulunmaya yardımcı olmaktadır. Ülkenin ekonomik dayanıklılık ve mali sağlamlık unsurları birlikte değerlendirildiğinde finansal sağlamlık konusunda analiz sonuçlarına ulaşılabilmektedir. Ekonomik değerlendirmeye ilişkin reel GSYİH büyümesi, GSYİH büyüme volatilitesi, nominal GSYİH ve kişi başı GSYİH verileri dikkate alınmaktadır. Ekonominin içsel gücü çeşitli şoklara karşı yüksek dayanıklılık sağlaması açısından önemlidir. Uzun süreli güçlü ekonomik dayanıklılık verilerine sahip ekonomilerde yüksek büyüme rakamları, iyi seviyede bir bütçe performansı, orta vadeli borç sürdürülebilirliği için yüksek gelir yaratma kapasitesi dikkat çeken özelliklerdendir. Kişi başına düşen GSYİH yüksek olması ise ekonomik rekabetin unsurlarından olan işgücü kalitesi ve sermaye kalitesinin göstergesi olarak değerlendirilmektedir (Moody’s Investor Service, Sovereign Rating Methodology, 2019).

Fitch Derecelendirme yaklaşımında, bir risk değerlendirme modeli ve bununla birlikte niteliksel değerlendirmeler kullanılmaktadır. Ülke riski derecelendirme modelinde ekonomi yapısal özellikleri, makroekonomik performans, politikalar ve beklentiler, kamu maliyesi ve dış finansman değerlendirmeleri ayrı ayrı yapılmaktadır. Ekonomi yapısal özellikleri ve makroekonomik performans değerlendirmelerinde iç ekonomik göstergeler dikkate alınmaktadır. Bu kapsamda, kişi başına düşen GSYİH, dünya GSYİH'dan aldığı pay, GSYİH büyüme volatilitesi ve büyümesi, tüketici fiyat endeksi değişkenleri incelenmektedir. İlgili ülke ekonomisinin dünya GSYİH'dan aldığı pay, ekonomik büyüklüğü değerlendirmek açısından önemlidir, küçük ölçekteki ekonomilerin kırılganlıklarının yüksek olduğu gözlenmektedir. Bu değişkenle birlikte GSYİH volatilitesi değişkeniyle kapsanmayan unsurlar da incelenebilmektedir. Ekonomide, hedeflenen düzeyde enflasyon oranları olması istikrarlı bir büyümenin temel faktörlerindendir. Kronik hale gelmiş enflasyonist ortamda ekonomik kırılganlıkların arttığı ve düşük ülke ratingleri oluştuğu gözlenebilmektedir (Fitch Ratings, Sovereign Rating Criteria, 2020).

\section{Model ve Veri}

Bu çalışmada, ülkelerin temerrüde düşme olayının gerçekleşmesiyle ilgili ülkenin yerel ekonomisindeki görünümleri ifade eden çeşitli veri setleri arasındaki ilişki, ikili lojistik regresyon yöntemiyle analiz edilmektedir.

Lojistik regresyon analizinde, bağımlı değişken kategorik olarak sınıflandırılmış bir veri setinden oluşmaktadır. İki sınıfa ayrılmış bir kategorik veri bulunması durumunda ikili lojistik regresyon yöntemi uygulanabilmektedir. Bu yöntemde, bağımlı değişkenin tahmincisi niteliğinde bağımsız değişkenler sürekli veya kategorik tipte değişkenlerden oluşabilmektedir (Field ve Miles, 2010, p. 232). 
Basit doğrusal regresyonda, sonuç değişkeni olan Y doğrusal bir denklemde tahmin edilmektedir.

$$
Y_{i}=b_{0}+b_{1} X_{1 i}+\varepsilon_{i}
$$

$Y$ ve $X_{l}$ 'in değerleri kullanılarak, denklemdeki bağımlı değişkenin en küçük kareler yöntemine göre gözlenen değerleri ve tahmini değerleri arasındaki fark minimuma indirilerek çözüm bulunmaktadır (Field,Miles, 2010, Sf.233).

Benzer şekilde, regresyon denkleminde, bağımlı değişkenin tahmini için birden fazla bağımsız değişken de kullanılabilmektedir.

$$
Y_{i}=b_{0}+b_{1} X_{1 i}+b_{2} X_{2 i}+\ldots+b_{n} X_{n i}+\varepsilon_{i}
$$

Lojistik regresyonda, bağımlı değişken $Y$ 'nin değerini bir veya birden fazla tahmini değişken olan $X_{i}$ ' den elde etmek yerine, $X_{i}$ bağımsız değişkenlerinin değerlerinden hareketle $Y$ 'nin gerçekleşme olasıllı̆̆ elde edilmektedir.

Tek bir tahmini değişkeni bulunan lojistik regresyon denkleminde $Y^{\prime}$ nin tahmin olasılığ aşağıdaki şekilde ifade edilmektedir.

$$
P\left(Y_{i}\right)=\frac{1}{1+\mathrm{e}^{-\left(\mathrm{b}_{0}+\mathrm{b}_{1} \mathrm{X}_{1 i}\right)}}
$$

Doğrusal regresyonda olduğu gibi lojistik regresyon denkleminde de birden fazla tahminci bulunabilmektedir. Birden fazla tahmincinin bulunduğu lojistik regresyon denklemi ise aşağıdaki şekilde ifade edilmektedir.

$$
P\left(Y_{i}\right)=\frac{1}{1+\mathrm{e}^{-\left(\mathrm{b}_{0}+\mathrm{b}_{1} \mathrm{X}_{1 \mathrm{i}}+\mathrm{b}_{2} \mathrm{X}_{2 \mathrm{i}}+\ldots+\mathrm{b}_{\mathrm{n}} \mathrm{X}_{\mathrm{ni}}\right)}}
$$

Model oluşturma aşamasında değişkenler stepwise ${ }^{1}$ yöntemiyle, belirli istatistiki esaslara göre analize dahil edilmektedir. Modele her bir değişken eklenmesinde, diğer değişkenlerin modelde kalıp kalmayacakları tekrar değerlendirilmektedir (Field ve Miles, 2010, p. 186).

$\mathrm{Bu}$ çalışmada, incelenen verinin bir kısmı validasyon çalışmasında kullanılmak üzere ayrılmıştır. Analiz edilen verinin \%70'i model geliştirme için, \%30'u geliştirilen modeli test etmek için kullanılmaktadır. Geliştirilen modelin doğruluğu ve kullanılabilirliğinin kontrolü

${ }^{1}$ Değişkenlerin hangi sırayla modele dahil olacağı kararına göre her bir değişkenin açılama gücüne katkısı incelenir. 
için farklı bir örneklem üzerinde tekrar çalıştırmasına validasyon (çapraz doğrulama) denmektedir (Field ve Miles, 2010, p. 196).

\subsection{Uygulamada Kullanılan Bağımsız Değişkenler}

Analize dahil edilen bağımsız değişkenler Tablo 1'de belirtilmektedir. Söz konusu değişkenler 2008-2017 yılları arasında, 20 adet ülkeyi (G20)² kapsama almaktadır.

Tablo 1: Çalışmada Kullanılan Bağımsız Değişkenlerin Açıklamaları

\begin{tabular}{lc}
\hline Veri & Değişken Açıklaması \\
\hline 1 & Tüketici Fiyatları (5 Yıllık Ortalama Değişim \%) \\
2 & Reel Efektif Döviz Kuru (\% Yıllık Değişim) \\
3 & Brüt Yurtiçi Tasarrufları (\% GSYH) \\
4 & Nominal GSYH Büyümesi (\%) \\
5 & Dolar Bazında Yerel Para Birimi (Yılsonu) \\
6 & Reel GSYH Büyümesi (\%) \\
7 & Brüt Yurtiçi Yatırımları (\% GSYH) \\
8 & Reel Efektif Döviz Kuru \\
9 & Brüt Ulusal Tasarruflar (\% Gayri Safi Milli Hasıla) \\
10 & Reel Kişi Başı GSYH Büyümesi (\%) \\
11 & Tüketici Fiyatları (Yıllık Ortalama Değişim \%) \\
12 & GSYH (Yerel Para Birimi) \\
13 & Gayri Safi Yurtiçi Hasıla (m USD) \\
14 & Tüketim Harcamaları (\% GSYH) \\
15 & Rezerv Para Statüsü \\
16 & Reel GSYH Büyümesi (5 yıllık Ortalama \%) \\
\hline
\end{tabular}

Analizde kullanılmak üzere veri setlerinde iyileştirme işlemleri yapılmıştır. Veri setlerinde bulunan eksik alanlar tamamlanmış ve aykırı değerlerde düzenlemeler yapılmıştır. Belirtilen iç ekonomi verilerinde 7 farklı değişkende medyan değerleri kullanılarak eksik veriler tamamlanmıştır.

Tablo 2: Veri Düzenleme Sonuçları 1

\begin{tabular}{lcc}
\hline Düzenlenen Değişken & Düzenleme Değeri & Eksik Veri Adedi \\
\hline IMP_v10 & 105.62 & 15 \\
IMP_v11 & 22.91 & 42 \\
IMP_v13 & 3,20 & 5 \\
IMP_v16 & 76.75 & 20 \\
IMP_v2 & 3,53 & 5 \\
IMP_v5 & 23,04 & 42 \\
IMP_v9 & 22.84 & 20 \\
\hline
\end{tabular}

2 Almanya, Amerika Birleşik Devletleri, Arjantin, Avustralya, Brezilya, Çin, Endonezya, Fransa, Güney Afrika, Güney Kore, Hindistan, İngiltere, İtalya, Japonya, Kanada, Meksika, Rusya, Suudi Arabistan, Türkiye. G20 ülkelerine ilaveten İspanya ve Yunanistan'da kapsama alınmıştır. 
Verilerde, ortalamadan sapan değerler üzerinden iyileştirme çalışmaları yapılmıştır. Veri setinde bulunan aykırı değerler üretilen sonuçlarda yanlış yorumlamalara sebebiyet verebilecektir. Bu düzenleme sırasında, veri kümesindeki en küçük ve büyük değerden sapan değerler olup olmadığ 1 kontrol edilmektedir (Skiena, 2017, p. 78).

Tablo 3: Veri Düzenleme Sonuçları 2

\begin{tabular}{lccccc}
\hline $\begin{array}{l}\text { Replace } \\
\text { Variable }\end{array}$ & Lower limit & $\begin{array}{c}\text { Lower } \\
\text { Replacement Value }\end{array}$ & Upper Limit & $\begin{array}{c}\text { Upper } \\
\text { Replacement Value }\end{array}$ & $\begin{array}{c}\text { Replacement } \\
\text { Counts }\end{array}$ \\
\hline REP_IMP_v10 & -30.99 & -30.99 & 258.95 & 258.95 & 8 \\
REP_IMP_v11 & -7.74 & -7.74 & 55.76 & 55.76 & 15 \\
REP_IMP_v13 & -117.03 & -117.03 & 129.90 & 129.90 & 2 \\
REP_IMP_v16 & 16.41 & 16.41 & 133.43 & 133.43 & 32 \\
REP_IMP_v2 & -31.82 & -31.82 & 43.17 & 43.17 & 3 \\
REP_IMP_v5 & -26.55 & -26.55 & 74.02 & 74.02 & 19 \\
REP_IMP_v9 & Oca.15 & Oca.15 & 46.59 & 46.59 & 26 \\
REP_v1 & -6151.53 & -6151.53 & 7079.30 & 7079.30 & 20 \\
REP_v12 & -10.16 & -10.16 & 13.59 & 13.59 & 18 \\
REP_v14 & -2711598188 & -2711598188 & 2973830231 & 2973830231 & 16 \\
REP_v15 & -5011723 & -5011723 & 6238446 & 6238446 & 17 \\
REP_v3 & -7.69 & -7.69 & Ara.48 & Ara.48 & 9 \\
REP_v4 & -24.38 & -24.38 & 26.22 & 26.22 & 14 \\
REP_v6 & -108.09 & -108.09 & 126.88 & 126.88 & 2 \\
REP_v7 & -6334.13 & -6334.13 & 7295.74 & 7295.74 & 17 \\
REP_v8 & -9.37 & -9.37 & 15.35 & 15.35 & \\
\hline
\end{tabular}

Gerekli düzenlemelerin yapılmasının ardından veriler üzerinde interaktif gruplama işlemi yapılmıştır. Interaktif gruplamada, istatistiksel olarak birbirine en yakın veriler optimal gruplama kümelerine ayrilmaktadır (Sas Doc., Developing Scorcards, 2013, p. 21). İnceleme kapsamına alınan verilerin weigt of evidence değerleri bağımlı değişkeni açıklama gücüne göre bir sıralamaya tabi tutulmuştur. Değişsenlerin GINI istatistikleri Tablo 4 'te gösterilmektedir. Analiz yapılırken GINI cut-off değeri \%10 olarak dikkate alınmıştır. 
Tablo 4: İç Ekonomi Değişkenleri Gini Sıralaması

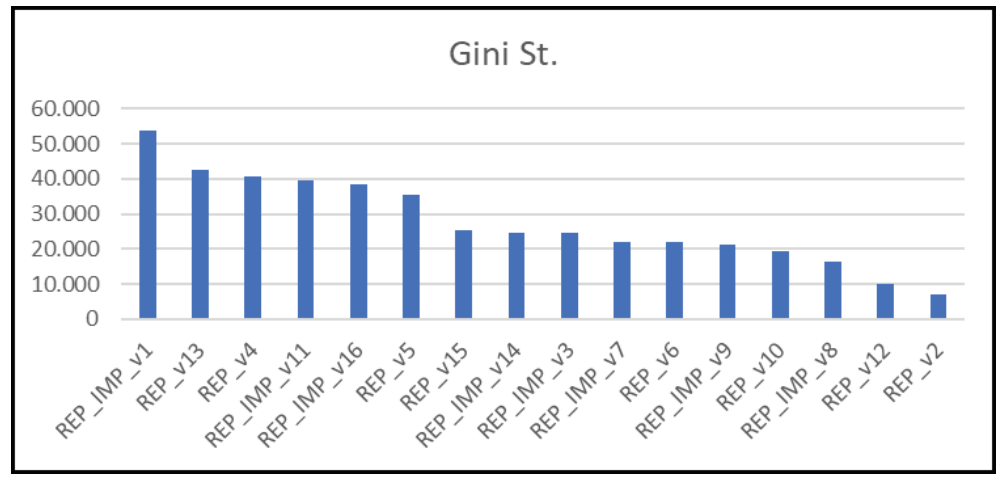

Kullanılan veri grupları regresyon analizine konu olmadan önce çoklu doğrusal bağlantıya neden olmaması için korelasyon varlığı incelenmiştir. Çalışma kapsamında \%60'ın üzerinde korelasyon gösteren değişkenler regresyon analizine dahil edilmemiştir (Field ve Miles, 2010, p. 199). Sadece modele konu edilecek değişkenlerin gösterildiği korelasyon matrisi Tablo 5'te sunulmaktadir.

Tablo 5: Modele Konu Değişkenlerin Korelasyon Matrisi

\begin{tabular}{lcccccccccc}
\hline & V1 & V13 & V16 & V5 & V15 & V14 & V7 & V10 & V8 & V2 \\
\hline V1 & 1,00 & & & & & & & & & \\
V13 & $-0,17$ & 1,00 & & & & & & & & \\
V16 & 0,26 & $-0,09$ & 1,00 & & & & & & & \\
V5 & 0,12 & $-0,05$ & 0,14 & 1,00 & & & & & & \\
V15 & $-0,33$ & 0,36 & $-0,37$ & $-0,14$ & 1,00 & & & & & \\
V14 & 0,13 & $-0,03$ & $-0,11$ & 0,00 & 0,01 & 1,00 & & & & \\
V7 & 0,14 & 0,06 & 0,42 & 0,12 & $-0,19$ & $-0,05$ & 1,00 & & & \\
V10 & 0,03 & 0,01 & 0,45 & 0,12 & $-0,15$ & 0,07 & 0,26 & 1,00 & & \\
V8 & 0,16 & $-0,03$ & 0,04 & 0,08 & $-0,04$ & $-0,13$ & 0,00 & $-0,03$ & 1,00 & \\
V2 & 0,19 & 0,00 & 0,12 & 0,03 & $-0,08$ & $-0,04$ & 0,05 & 0,09 & 0,21 & 1,00 \\
\hline
\end{tabular}

\subsection{Uygulamada Kullanılan Bağımlı Değişken Seçimi}

Bağımlı değişkenler, incelenen ülkelerin 2008-2017 yılları arasında temerrüde düşme verileri olarak ele alınmıştır. Söz konusu kategorik veri oluşturulurken Bank of Canada ve Bank of England tarafından geliştirilen ülkeler bazında ve borç türleri bazında oluşturulan temerrüt verilerinden faydalanılmıştır (Beers ve Maglagnit, 2019). Söz konusu veri tabanında, IMF, IBRD, döviz cinsinden banka kredileri, banka bonoları, yerel para birimindeki borçlanmaları gibi pek çok borç türü kapsama alınmaktadır. 
Tablo 6: Temerrütteki Ülke Borçlarının Dünya Toplam Borcuna ve Dünya GSYİH'na Oranı

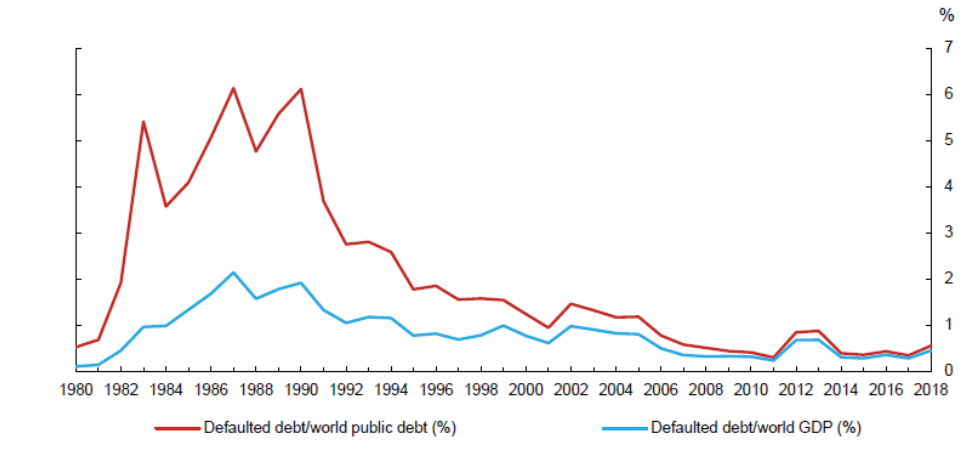

Kaynak: Bank of Canada ve Bank of England Veritabanı

Temerrüt verisinin oluşmasının temel varsayımları arasında ülkelerin temerrüde konu olma süreleri ve ödeme güçlügüune konu olan borç türleri de dikkate alınmaktadır (Cruces, Trebesch, 2013).

\section{Uygulama Sonuçları ve Bulgular}

Uygulanan lojistik regresyon model ve validasyon sonuçlarının açıklanmış ve karşılaştırması yapılmıştır.

Tablo 6: Model Yakınsaklık Durumu

Model Yakınsama Durumu

Convergence criterion (GCONV=1E-6) satisfied.

Geliştirme modelinin ve validasyon için ayrılan veriyle elde edilen modelin yakınsadığı sonucuna ulaşılmıştır. Yakınsama durumu Maksimum Olabilirlik Tahmini (MLE) üzerinden incelenmektedir.

Tablo 7: Model Hipotez Testi

\begin{tabular}{|c|c|c|c|c|c|c|}
\hline & & $\begin{array}{c}\text { Intercept } \\
\text { Only }\end{array}$ & $\begin{array}{c}\text { Intercept and } \\
\text { Covariates }\end{array}$ & $\begin{array}{c}\text { Likelihood Ratio } \\
\text { Chi-Square }\end{array}$ & DF & Pr $>$ ChiSq \\
\hline Model 1 & $\begin{array}{l}-2 \text { Log Like- } \\
\text { lihood }\end{array}$ & 1373.130 & 886.689 & 486.4407 & 5 & $<.0001$ \\
\hline $\begin{array}{l}\text { Model } 2 \\
\text { Validasyon }\end{array}$ & $\begin{array}{l}-2 \text { Log Like- } \\
\text { lihood }\end{array}$ & 961.375 & 632.338 & 329.0378 & 5 & $<.0001$ \\
\hline
\end{tabular}

Geliştirme modeli ve validasyon modelinde sabit katsayı dışında değişken anlamlılığını test eden hipotez testi sonucuna göre $H_{0}: \beta=0$ hipotezi reddedilmektedir. 
Tablo 7: AIC Değişim Grafiği

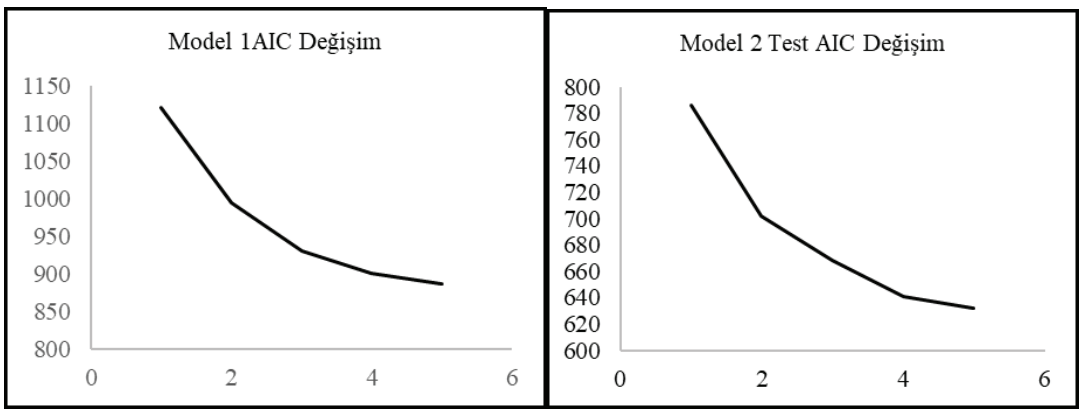

AIC kriterinde azalma görülmektedir. Modellere eklenen değişkenler açıklama gücünü artırıcı yönde etki etmektedir.

Tablo 8: Lojistik Regresyon Model Tahmini

\begin{tabular}{lcccccccc}
\hline \multirow{2}{*}{ Variable } & DF & Estimate & $\begin{array}{c}\text { St. } \\
\text { Hata }\end{array}$ & $\begin{array}{c}\text { Wald } \\
\text { Chi- } \\
\text { Square }\end{array}$ & $\begin{array}{c}\text { Pr> } \\
\text { ChiSq }\end{array}$ & $\begin{array}{c}\text { Standardized } \\
\text { Estimate }\end{array}$ & Exp(Est) \\
\hline \multirow{5}{*}{ Model 1 } & & & & & & & \\
& Intercept & 1 & -1.0089 & 0.0922 & 119.72 & $<.0001$ & & 0.365 \\
& WOE_REP_IMP_v8 & 1 & -1.2918 & 0.2515 & 26.38 & $<.0001$ & -0.2359 & 0.275 \\
& WOE_REP_IMP_v1 & 1 & -0.8526 & 0.0821 & 107.73 & $<.0001$ & -0.5567 & 0.426 \\
& WOE_REP_IMP_v7 & 1 & -0.6308 & 0.1717 & 13.50 & 0.0002 & -0.1601 & 0.532 \\
& WOE_REP_v13 & 1 & -0.9794 & 0.1004 & 95.19 & $<.0001$ & -0.5845 & 0.376 \\
Model 2 & WOE_REP_v5 & 1 & -0.8264 & 0.1266 & 42.60 & $<.0001$ & -0.4937 & 0.438 \\
Validasyon & Intercept & 1 & -0.9366 & 0.1060 & 78.06 & $<.0001$ & & 0.392 \\
& WOE_REP_IMP_v8 & 1 & -1.4240 & 0.3000 & 22.52 & $<.0001$ & -0.2604 & 0.241 \\
& WOE_REP_IMP_v1 & 1 & -0.8385 & 0.0964 & 75.67 & $<.0001$ & -0.5546 & 0.432 \\
& WOE_REP_IMP_v7 & 1 & -0.6113 & 0.2040 & 8.98 & 0.0027 & -0.1556 & 0.543 \\
& WOE_REP_v13 & 1 & -0.9233 & 0.1140 & 65.60 & $<.0001$ & -0.5545 & 0.397 \\
& WOE_REP_v5 & 1 & -0.6966 & 0.1440 & 23.39 & $<.0001$ & -0.4118 & 0.498 \\
\hline
\end{tabular}

Olasılık değeri $0.05^{\prime}$ in altında olan açıklama gücüne sahip değişkenlerden oluşan model 1 ve model 2 tahmini gösterilmektedir.

Geliştirme verisiyle oluşturulan Model 1'in açıklama gücünü ifade eden GINI değeri 0.784 olarak elde edilmiştir. Validasyon verisiyle elde edilen modelin GINI değeri ise 0.744 olarak elde edilmiştir. Model GINI değerleri arasındaki fark \%5 olarak hesaplanmıştır ve kritik eşik olan \%10 değerini aşmamaktadır. Validasyon sonucunda yüksek tutarlılığa sahip bir sonuç elde edilmiştir. 
Tablo 9: Regresyon Sonucu Geçiş Matrisi

\begin{tabular}{ccccc}
\hline & \multicolumn{3}{c}{ Çıktı Değişken } & Başarılı Tahmin \\
\cline { 2 - 4 } & & $\mathbf{0}$ & \multirow{2}{*}{$\% 81$} \\
\multirow{2}{*}{ Hedef Değişken } & 0 & $\% 64$ & $\% 7$ & \\
& 1 & $\% 11$ & $\% 17$ & \\
\hline
\end{tabular}

Geçiş matrisinde görüldüğü üzere incelenen veri setinde temerrüt etmeyen \%64'lük bir veri kitlesinin model tahmini temerrüt oluşmayacağı yönündedir. Aynı şekilde veri setindeki $\% 17$ 'lik bir temerrüt kitlesi model tarafından da temerrüt sınıfında tahmin edilmiştir. Modelin başarılı tahmin değeri \%81 olarak hesaplanmıştır.

\section{Sonuç}

Analiz sonucunda ele alınan değişken kümesi içerisinden reel efektif döviz kuru, tüketici fiyatları endeksi, brüt yurtiçi yatırımlar, dolar (USD) cinsinden GSYİH ve USD bazında yerel para birimi, yani ilgili yıldaki kur bilgisi değişkenleri üzerinden açıklama gücü yüksek bir model oluşturulmuştur. Modelde anlamlı olan ve iç ekonomiyle ilgili dinamikleri ifade eden bu veriler ile ülkenin temerrüt verisi arasındaki olasılıksal ilişki belirlenmiştir. USD cinsinden GSYİH verisinin modeldeki ağırlığ $\% 29$, tüketici fiyatları endeksi verisinin \%27, USD bazında yerel para birimi yani ilgili yıldaki kur bilgisi verisinin ise \%24’tür.

Oluşturulan model sonucunda temerrüt olasılığ 1 ve temerrüt etmeme olasılığ bin default flag_0) sonuçları elde edilmiştir. Çalışmada G20 ülkeleri kapsama alınmıştır. Aşağıda sunulan grafiklerden, Grafik 2'de AB üyesi ülkeler, Arjantin ve Hindistan'la, Türkiye'nin temerrüt etmeme olasılığını ifade eden skor puanı gösterilmektedir. Fransa, Almanya, İtalya, İspanya ve Yunanistan'ın skor değerleri 0,99 ve üzeri değerle sağlıklı bir iç ekonomik gösterge sunmaktadır. Gelişmekte olan ülkeler arasında yer alan Arjantin ve Hindistan görüldüğü üzere AB üyesi ülkelerden ayrışan daha düşük skor değerlerine sahiptir, dolayısıyla temerrüt etme olasılığı daha yüksek seyretmiştir. Türkiye'nin skor değeri 2014 yılına kadar Arjantin ve Hindistan'dan daha iyi bir skalada oluşmakla birlikte, 2014 yılından itibaren Hindistan pozitif ayrışmıştır. 
Grafik 2. Seçilmiş Ülkeler Temerrüt Etmeme Olasılıkları I

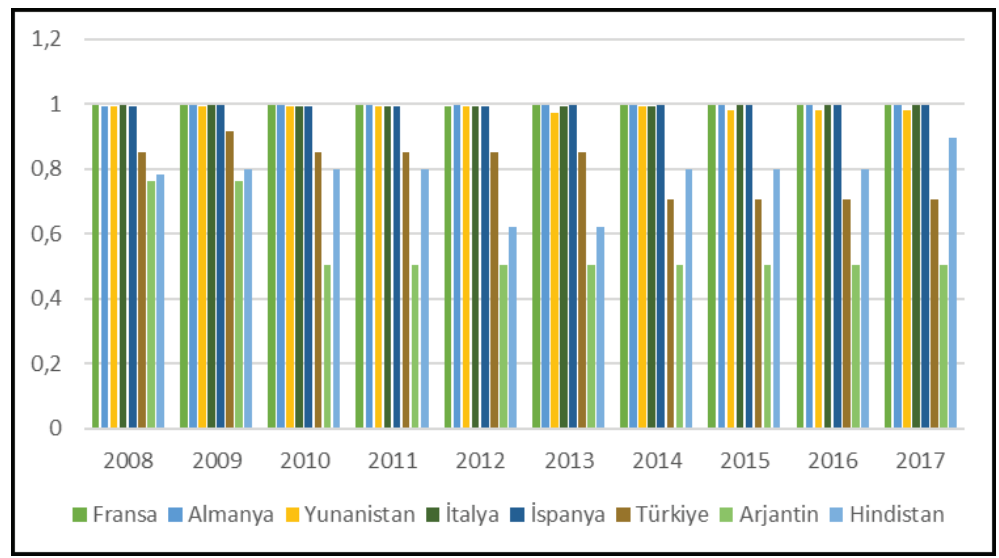

Türkiye'nin temerrüt etmeme skor değeri, 2014 yılına kadar 0,85 skalasında bulunmaktayken, bu yıldan sonra 0,70 seviyelerine gerilemiştir. Bu yıllara ilişkin kaynak veriler incelendiğinde 2013 yılından itibaren dolar kuru seviyesinde $\% 30$ ve üzerinde artışlar olduğu, kur artışının etkisiyle USD cinsinden GSYİH seviyelerinde azalma olduğu görülmektedir. Bu durum ise göstergelere temerrüt olasılığını artırıcı yönde yansımıştır.

Grafik 3. Seçilmiş Ülkeler Temerrüt Etmeme Olasılıkları II

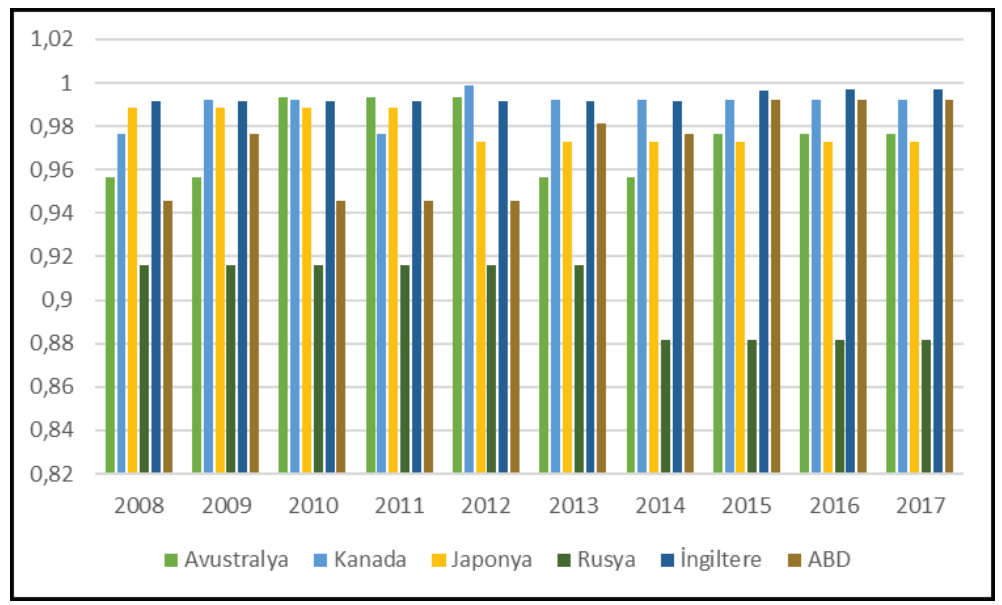

Avustralya, Kanada, Japonya, İngiltere ve ABD'nin temerrüt etmeme olasılığ 0,95 skalası üzerinde seyretmiştir. Bu ülkeler grubunda, Rusya görece olarak daha riskli bir görünüm sergilemekle birlikte en düşük 0,88 seviyesine gerilemiştir. Rusya'nın kaynak verileri incelendiğinde 2014 yılından itibaren kur artışları dikkat çekicidir ve yükselen kur nedeniyle USD cinsinden GSYİH sevilerinde azalma görülmektedir. 
İç ekonomik göstergelerden hareketle yapılan analizde, reel efektif döviz kuru, tüketici fiyatları endeksi, brüt yurtiçi yatırımlar, USD cinsinden GSYİH ve kur değişiklikleri verileri ile ülke temerrüt olasılığı arasındaki ilişki açıklanmıştır. Sonuçlar değerlendirildiğinde, rezerv paraya sahip olmayan ve diş riskler karşısında kur değişiklikleri sergileyen ülkelerin hem kur artışlarından hem de USD bazında GSYİH azalmasından kaynaklı olarak temerrüt etme olasılıklarında artış olduğu görülmektedir.

Hakem Değerlendirmesi: Dış bağımsız.

Çıkar Çatışması: Yazar çıkar çatışması bildirmemiştir.

Finansal Destek: Yazar bu çalışma için finansal destek almadığını beyan etmiştir.

Peer-review: Externally peer-reviewed.

Conflict of Interest: The author has no conflict of interest to declare.

Grant Support: The author declared that this study has received no financial support.

\section{Kaynakça/References}

Afonso, A. (2003). Understanding the determinants of sovereign debt ratings: Evidence for the two leading agencies. Journal of Economics and Finance, 27(1), 56-74.

Afonso, A., \& Gomes, P. (2011). Do Fiscal Imbalances Deteriorate Sovereign Debt Ratings? Revue 'Economique, 62(6):1123-1134.

Afonso, A., Agnello, L., \& Furceri, D. (2010). Fiscal policy responsiveness, persistence, and discretion. Public Choice, 145(3-4), 503-530.

Bank of Canada Default Data. (2020, 01 Eylül). Erişim Adresi: https://www.bankofcanada.ca/wp-content/ uploads/2019/09/crag-database-update-27-09-19.xlsx

Beers, D., \& de Leon-Manlagnit, P. (2019). The BoC-BoE sovereign default database: what's new in 2019.

Butler, A., \& Fauver, L. (2008). Institutional Environment and Sovereign Credit Ratings, Financial Management Vol. 35, Issue 3.

Cantor, R., \& Packer, F. (1995). Sovereign Credit Ratings. Current Issues in Economics and Finance, 1(Jun).

Cantor, R., \& Packer, F. (1996). Determinants and Impact of Sovereign Credit Ratings. Economic Policy Review, (Oct):37-53.

Cruces, J. J., \& Trebesch, C. (2013). Sovereign defaults: The price of haircuts. American economic Journal: macroeconomics, 5(3), 85-117.

Sas Documentary. (2013). Developing ScoreCards. (2020, 15 Ekim). Erişim Adresi:https://support.sas.com/ documentation/cdl/en/emcsgs/66008/PDF/default/emcsgs.pdf

Eaton, J., \& Fernandez, R. (1995). Sovereign Debt, NBER Working Paper Series N:5131.

Field, A., \& Miles, J. (2010). Discovering Statistics Using SAS,Sage Publication, London.

Haque, N., Mark, N. C., \& Mathieson, D. J. (1998). The Relative Importance of Political and Economic Variables in Creditworthiness Ratings", IMF Working Paper: 1-13.

Hill, P., Bissoondoyal-Bheenick, E., \& Faff, R. (2017). New Evidence on Sovereign to Corporate Credit Rating Spill-overs, IRFA,30104-7.

Infrangilis (2012). Rating Sovereign Raters, Credit Rating Agencies - Political Scapegoats or Misguided Messengers. 
Juttner, J.D. \& McCarthy, J. (1998). “Modeling a rating crisis.” Mimeo, Macquarie University, Sydney.

Kraay, A., \& Nehru, V. (2006). When is external debt sustainable?. The World Bank Economic Review, 20(3), 341-365.

Manasse, P., Roubini, N., \& Schimmelpfennig, A. (2003). Predicting Sovereign Debt Crises, WP/03/221.

Manasse, P., \& Roubini, N., (2009). "Rules of thumb" for sovereign debt crises. Journal of International Economics, 78(2), 192-205.

Moody's History A Century of Market Leadership. (2020, 02 Aralık). Erişim Adresi: https://www.moodys.com/ Pages/atc001.aspx

Moody’s Market Segment. (2020, 03 Aralık). Erişim Adresi: https://www.moodys.com/researchandratings

Moody's Investor Service. (2017). Rating symbols and definitions. (2020, 10 Ekim). Erişim Adresi:https://www. moodys.com/researchdocumentcontentpage.aspx?docid=PBC_79004

Moody's Investor Service. (2019). Sovereign Ratings Methodology. (2020,10 Ekim). Erişim Adresi: https://www. moodys.com/researchandratings/methodology/003006001/rating-methodologies/methodology

Panizza, U., Sturzenegger, F., \& Zettelmeyer, J. (2009). The Economics and Law of Sovereign Debt and Default, Journal of Economic Literature, 47:3, 1-47.

Fitch Ratings. (2020). Sovereign rating criteria: Master criteria. (2020, 15 Ekim). Erişim Adresi:https://www. fitchratings.com/research/sovereigns/sovereign-rating-criteria-26-10-2020

S\&P Global Ratings. (2018). Guide to Credit Rating Essentials. (2020, 15 Ekim). Erişim Adresi:https://www. spglobal.com/ratings/_divisionassets/pdfs/guide_to_credit_rating_essentials_digital.pdf

Reinhart, M. (2002). Default, Currency Crıses And Sovereıgn Credıt Ratıngs, NBER Working Paper Series N: 8738 .

Roubini, N. (2001). Debt Sustainability: How to Assess Whether a Country is Insolvent, New York University.

S\&P Global Ratings. (2017). Global Ratings Definitions. (2020, 12 Ekim). Erişim Adresi: https://www.spglobal. com/ratings/en/research/articles/190705-s-p-global-ratings-definitions-504352

S\&P Global Ratings.(2017). Sovereign Rating Methodology. (2020, 12 Ekim). Erişim Adresi: https://www. spratings.com/documents/20184/4432051/Sovereign+Rating+Methodology/5f8c852c-108d-46d2-add1$4 \mathrm{c} 20 \mathrm{c} 3304725$

Standart\&Poors, About S\&P Global Ratings. (2020,01 Aralık). Erişim Adresi: https://www.spglobal.com/ratings/ en/about/index.aspx

Steven S. Skiena. (2017). The Data Science Design Manual, Springer, USA.

Trebesch, C. (2009). "The Cost of Aggressive Sovereign Debt Policies: How Much is the Private Sector Affected?" International Monetary Fund (IMF) Working Paper 09/29. 